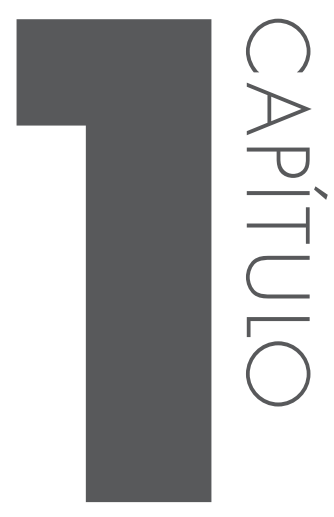

\title{
OS RISCOS DA FORMALZAC̣ÃO PARA EMPRESAS DE PEQUENO PORTE
}

Caetano, Frederico Mendes 1 *;

Fernandes, Queli Silvério 2;

Resende, Maryele L. 3;

Rosalem, Vagner 4

1 Aluno de Mestrado Profissional em Gestão Organizacional, UFG - Catalão.

2 Aluno de Mestrado Profissional em Gestão Organizacional, UFG - Catalão.

3 Aluno de Mestrado Profissional em Gestão Organizacional, UFG - Catalão.

4 Professor Dr. Mestrado Profissional em Gestão Organizacional, UFG - Catalão.

* email: frederico_adm@hotmail.com 
Resumo: $\bigcirc$ objetivo deste artigo é discutir sobre a influência da estrutura organizacional no desempenho das atividades das organizações e seu reflexo no comportamento organizacional, analisando os pontos negativos do excesso de formalização para pequenas empresas, não deixando de entender também que a falta de formalização pode inviabilizar a empresa de diversas formas, como por exemplo, no atendimento a seus clientes, a legislações em vigor, fornecedores e até mesmo aos direitos de seus funcionários. Assim, é importante analisarmos também que uma estrutura organizacional bem fundada é um pré-requisito da "saúde organizacional", mas não é a saúde em si que irá determinar a clareza ou a perfeição da estrutura, mas o que assegura o bom resultado da organização será o desempenho obtido através da boa gestão desta organização.

\section{Palavras-chave: Estrutura Organizacional; formalização}




\section{Introdução}

A estrutura organizacional sempre foi bastante estudada e analisada, por diversos períodos da história, principalmente pela administração. Mesmo com este vasto estudo, sempre surge necessidades para adaptação, evolução ou mesmo restruturação dos modelos rígidos já conhecidos e experimentados, pois estes não estão alcançando os objetivos a que foram propostos, ou seja, não satisfazem aos anseios e desejos organizacionais.

Assim, a extensa literatura disponível sobre organizações, métodos e sistemas organizacionais, observa-se um foco nos tipos de estruturas e suas relações com indicadores de eficácia e eficiência. Teorias de Organizações e Métodos como a ressaltada por Mintzberg (1995) apontam que toda atividade humana organizada dá origem a duas exigências 
fundamentais e opostas: a divisão do trabalho em várias tarefas a serem executadas e a coordenação dessas tarefas para que se obtenham os resultados esperados.

É importante também se analisar o seguinte aspecto, onde cada vez mais se fala sobre administração, planejamento, análise e controle de processos, além de diversos outros temas como globalização, informatização, recursos escassos e sua melhor utilização. Vemos também como a formalização, pode influenciar no sucesso ou falência de uma pequena empresa.

Assim, o presente artigo tem como objetivo discutir sobre a influência da estrutura organizacional no desempenho das atividades organizacionais e seu reflexo no comportamento organizacional, analisando os riscos do excesso de formalização para empresas de pequeno porte.

A produção de componentes utilizando chapas metálicas e técnicas que dão forma aos sólidos é de grande significância, como na aplicação em indústria automotiva, modelagem de recipiente, construção de edifícios ou na produção de eletrodomésticos.

As prensas, com a sua capacidade para conduzir com precisão as atividades de conformação metálica, tornaram-se um símbolo da metalurgia e do processo de produção moderno. É neste contexto que o freio de estampagem desempenha papel fundamental em determinadas operações de estampagem, em que grandes esforços de conformação mecânica estão envolvidos.

Para que determinadas peças sejam estampadas com qualidade, é essencial que o fluxo de material conformado no interior da matriz seja bem controlado. Normalmente este fluxo é controlado pela força do prensa-chapas, no entanto, quando a magnitude da força necessária é excessivamente grande, ao ponto de poder causar danos à peça ou a máquina utilizada, são utilizados os freios de estampagem, que têm a função de prover a força de retenção necessária para controlar o fluxo de material para dentro da matriz (HUG, 2004)

O freio de estampagem, também conhecido como quebra-rugas ou Drawbeads, consiste em um pequeno aparato localizado na superfície do prensa- chapas ou na borda da matriz e um sulco localizado na superfície oposta, conforme mostra a Figura 1.

\section{Propósito}

O propósito deste artigo é fazer um estudo teórico sobre a influência da formalização e burocratização sobre a estrutura organizacional, e consequentemente seus reflexos positivos e negativos sobre o desempenho das atividades organizacionais das empresas de pequeno porte. 
Segundo o SEBRAE (2012), as pequenas e médias empresas brasileiras representam $20 \%$ do PIB, são responsáveis por $60 \%$ dos 94 milhões de empregos no País, e isto representa, respectivamente, $\mathrm{R} \$ 700$ bilhões de reais, 5,7 milhões de MPEs e 56,4 milhões de empregos. Assim, a relevância das pequenas e médias empresas é facilmente compreendida na citação acima do SEBRAE, sendo de suma importância e relevância o estudo sobre este aspecto.

É notório que a organização não começa com a estrutura, que não existe um único modelo certo ou universal, mas que cada empresa precisa fazer o seu projeto estrutural baseado nas atividades fundamentais adequadas à sua missão e suas estratégias. E que operação, inovação e administração devem estar estruturadas e abrigadas sob o mesmo teto organizacional. E ainda, que a estrutura organizacional precisa tanto ser enfocada nas atividades como enfocada nas pessoas de forma a ter a direção da autoridade bem como da responsabilidade (DRUCKER, 1975).

Estruturas organizacionais não são fixas, elas formatam aquilo que ocorre dentro das organizações e são formatadas - em retorno - pelo que ocorre dentro das organizações (HALL, 1998). Esse aspecto recíproco da estrutura organizacional em relação às ações que a permeiam ressalta o fato de que as organizações tendem a serem conservadoras por natureza. Há uma busca pela estabilidade das relações bem sucedidas ou desejadas. Suas estruturas, ao mesmo tempo, representam e são constituídas pelas interações que permeiam a organização. Estrutura não garante total conformidade com o que se deseja que ocorra, mas tem o propósito de prevenir comportamentos aleatórios.

Na concepção de uma estrutura, há de se considerar a existência de uma justaposição de diversas dimensões internas e externas à organização. Interpretações para soluções tecnológicas, mudanças políticas e sociais dentro e fora das organizações influenciam o modo ou as formas de estruturação. Há, portanto, um desdobramento dialético das relações entre os agentes da organização (HALL, 1998). Isso afeta as formas estruturais. Estrutura, dessa maneira, é vista como uma dimensão continuamente emergente. Essa abordagem traz à tona a questão das relações de poder influenciando direta ou indiretamente a estrutura organizacional.

Devido à concorrência cada vez maior, as empresas tendem a buscar instrumentos de gestão para garantir mais qualidade em seus produtos e serviços. Tendem assim, a adequar seus processos para se reduzir custos, alcançando melhores resultados. Dentro desse contexto é imperativo algum grau de formalização da estrutura organizacional, por mínimo que seja, permeando as atividades da empresa. Ocorre que se a estrutura formal for um fator de dificuldade para que as decisões fluam dentro da organização, ela - a estrutura - deixa de exercer seu papel de organizadora, passando a representar um fator de entrave à melhoria dos resultados desejados.

Assim, podemos perceber a importância e interesse em estudar organizações e 
pela convicção subjacente de que estrutura ou estruturas organizacionais herdadas ou impostas, ou ainda, adotadas sem critérios racionais, dificilmente serão apropriadas às necessidades do empreendimento no qual estão inseridas. Acima de tudo, a estrutura que, por melhor que pareça ser a mais adequada, por si não assegurará desempenho e resultados. E ainda, a estrutura inadequada é uma garantia do não desempenho (DRUCKER, 1975).

\section{Revisão da Liferałura}

Segundo Chiavenato (2005), cada vez mais os desafios do mundo mais globalizado e a velocidade, muitas vezes agressiva e implacável da mudança, conduzem as organizações a um sentido de emergência quanto ao ajustamento e adaptabilidade, no sentido de adaptar e sobreviver no ambiente de negócios. Dessa forma, se as empresas não buscarem se adaptar aos novos desafios estarão correndo grandes riscos de não sobreviverem.

Desta forma, a estrutura organizacional busca adaptar a empresa ao ambiente, segundo Maximiano (1997), não significando apenas torná-la mais capaz de enfrentar seus concorrentes, porque os desafios vêm de diversas fontes. Evolução da tecnologia, exigências dos sindicatos, controle governamental e pressões da sociedade são circunstâncias que oferecem desafios e oportunidades para todos os tipos de empresas. Ou seja, ambiente externo e interno interagem e as decisões tomadas em cada uma dessas instâncias permeiam a estrutura da organização enquanto formalização da divisão de tarefas.

Formalização tem que ser vista como um fator crítico de sucesso para a organização. Um aspecto importante se refere ao grau em que uma organização é formalizada é uma indicação das perspectivas de seus tomadores de decisão em relação aos membros da organização. Se é desejado que os membros sejam capazes de exercer julgamento e autocontrole, a formalização será baixa; se são vistos como sendo incapazes de tomar suas próprias decisões e requerem um maior número de regras para nortear seu comportamento, então a formalização será alta. Formalização diz respeito ao controle organizacional sobre os indivíduos e, portanto, tem um significado ético e político além de ser um componente estrutural (HALL, 1998). Ela pode guiar os indivíduos, uma vez que procedimentos formais podem auxiliar pessoas a executar seu trabalho. Ao mesmo tempo, ela é coercitiva, na medida em que as pessoas são impelidas a segui-las.

Desta forma, a formalização implica ao grau em que as tarefas ou os cargos são padronizados na organização. Uma tarefa ou um cargo com grande grau de formalizado dá ao funcionário desta organização pouco poder de decisão, sobre o quê, 
quando e como será feito seu trabalho (ROBBINS, 2007). É plausível esperar que os funcionários de uma organização com alto grau de formalização controlem os mesmos insumos exatamente do mesmo modo, resultando em uma produção consistente e uniforme. Existem descrições explícitas, uma série de regras organizacionais e procedimentos claramente definidos, abrangendo processos de trabalho em organizações dotadas de extrema formalização (ROBBINS, 2007). Onde a formalização é baixa, os comportamentos de trabalho são relativamente não programados e os funcionários dispõem de bastante liberdade para exercerem seu arbítrio em seu trabalho.

É possível constatar que a liberdade de decisão um indivíduo no trabalho é inversamente proporcional à quantidade de comportamento que é pré-estabelecida pela organização, quanto maior a padronização, menor a contribuição do funcionário sobre como seu trabalho será realizado (ROBBINS, 2002). A padronização não elimina somente a possibilidade de que os trabalhadores se envolvam em comportamentos alternativos, como também a necessidade de considerarem outras opções.

Nesta análise, segundo Chiavenato (2005), podemos perceber uma alteração nos procedimentos das organizações atuais, no sentido de ter foco cada vez maior no alcance dos objetivos, resultados e metas, reduzindo assim antigos controles externos, como regras, regulamentos, procedimentos, horários de trabalho, ou seja, substituindo os velhos conceitos, para novos conceitos, como valores organizacionais, missão da organização e foco no cliente.

Motta (2002) analisa alguns autores estruturalistas de grande importância na teoria das organizações, a saber, Robert K. Merton, Phillip Selznick, Alvin Gouldner, Michel Crozier e Peter Blau que criticam e analisam a forma organizacional estruturalista e essencialmente burocrática concluindo que existe um distanciamento entre o modelo oficial, burocrático e as práticas informais, onde de um lado temos a racionalidade e o cálculo, e do outro as práticas informais, que são relacionados à impessoalidade, onde os efeitos deste distanciamento acarretariam consequências "disfuncionais" para a empresa, indo ao contrário da ideia de eficiência descrita como a "melhor maneira".

Um aspecto a ser observado neste sentido das disfunções sob a ótica da empresa é a nova forma de internacionalizar as regras e apego aos regulamentos, como vemos abaixo:

As normas e os regulamentos passam a se transformar de meios em objetos. Passam a ser absolutos e prioritários: os funcionários adquirem "viseiras" e esquece que a flexibilidade é uma das principais características de qualquer atividade racional, não por possuir conhecimento de suas tarefas, mas por conhecer perfeitamente as normas e os regulamentos que dizem respeito ao seu cargo ou função. (CHIAVENATO, 201 1:252) 
Outro ponto que deve ser observado, segundo Mota (2002), é que os teóricos estruturalistas afirmam que utilizar regras e modelos de outros grupos ou seguir as regras apenas porque se considera que é necessário segui-las, como no caso de uma personalidade burocrática exacerbada, são estratégias que geram efeitos indesejados para a organização. As regras e formas organizacionais criadas pelas organizações e agentes supra organizacionais - tais como associações governamentais, associações de classe etc. - passam a influenciar e exercer pressões sobre as estruturas organizacionais dos sistemas inseridos naquele meio ambiente institucional.

Uma consequência desta formalização e burocratização são que as regras e estruturas organizacionais operam de modo indireto e não determinam o comportamento dos chamados atores sociais, mas induzem jogos de poder e comportamentos. Conforme os importantes autores estruturalistas mencionados por Motta (2002) observa-se que em organizações burocráticas os funcionários irão evitar os aspectos desagradáveis dos procedimentos oficiais e mudar a sua conduta a fim de adotar atitudes que julguem mais apropriadas ou convenientes para a situação, dependendo de seus valores como grupo organizacional.

Segundo Motta (2002), de acordo com a concepção estruturalista, as relações entre as partes da organização são de grande importância, o que leva os autores, analistas e críticos a darem um destaque todo especial às relações entre organização formal e organização informal na análise de qualquer tipo de organização.

Segundo Mintzberg (1995), independente dos meios de formalização, que podem ser: função, fluxo de trabalho ou normas, sempre se terá o mesmo efeito sobre a pessoa que executa o trabalho, ou seja, seu comportamento é regulamentado. Segundo pesquisas - coordenadas pelo próprio Henry Mintzberg - feitas por estudantes da McGill University, constatou-se que os organogramas especificavam as estruturas formais, mas não descreviam os padrões de comunicação e as relações de poder que realmente ali existiam. Tais relações eram simplesmente fluidas em demasia para serem formalizadas, pois a estrutura tinha de naturalmente evoluir e continuamente mudar. Finalmente, deveria ser observado que organizações com forte orientação estruturalista criam mecanismos de trabalho naturais independentes com tipos de estruturas informais e diferentes da formal com o fim de perfazer suas tarefas e trabalhos específicos.

Isso pode ser explicado pelo fato de que profissionais trazem à organização um conjunto de paradigmas externos - derivados de suas profissões - pelos quais podem direcionar seus próprios comportamentos. A presença de formalização é, portanto, uma redundância normativa, que é provavelmente percebida como menos válida que as normas da profissão envolvida. Para profissionais, então, quanto maior o grau de formalização organizacional, maior a probabilidade de alienação do trabalho (HALL, 1998). Isso significa que há uma grande insatisfação com o trabalho naquelas 
organizações em que as tarefas são rigidamente estruturadas; rigidez pode levar a fortes sentimentos de insatisfação no trabalho, mas não parece ter um impacto deletério nas relações sociais dentro da organização.

Percebe-se que neste momento a organização tem dois caminhos a seguir: Primeiro, se é permitida pouca liberdade aos seus membros, eles estarão susceptíveis a sentirem-se oprimidos, alienados, burocratizados e a engajarem-se às regras pelas próprias regras. Segundo, se por outro lado é permitida grande liberdade, o comportamento poderia tornar-se errático e - do ponto de vista organizacional - irrelevante. O fator básico aqui é o tipo de delineamento para o comportamento que os próprios indivíduos trazem à organização. Quanto mais padrões de ação são trazidos pelos indivíduos, menor a necessidade por padrões baseados na organização.

\section{Considerações Finais}

Para poderem funcionar adequadamente, as organizações precisam de uma estrutura que sirva de base para conter e integrar os órgãos, pessoas, tarefas, relações, recursos e etc. Assim isto, influenciará diretamente na forma com que a organização obterá seus objetivos e metas, além da realização das atividades.

Neste sentido, a organização não tem todos os mecanismos para identificar as pessoas, no sentido de saber, toda a bagagem de conhecimento e experiências que as mesmas adquiriram durante o seu processo de formação, não apenas na vida pessoal como profissional. Mesmo a consideração de critérios relativamente simples como à relevância das categorias profissionais conhecidas é insuficiente para predizê-lo, visto que nem todos os membros de uma profissão agem de acordo com seus padrões e nem todos os padrões profissionais são bons para todas as organizações.

O nível de formalização e estruturação das atividades têm efeitos determinantes nos níveis de satisfação dos membros da organização e no clima organizacional percebido. Ao mesmo tempo, restrições de papéis e reforço de regras têm efeitos negativos. Regras bem delineadas - a princípio - proporcionam uma diretriz mais cheia de sentido para o trabalho. E a formalização reduz a ambiguidade de ações.

A relação entre os níveis de formalizações e as expectativas dos membros das organizações é a chave para equacionar as reações dos indivíduos às estruturas organizacionais formalizadas. Assim, cada empresa deve analisar seus processos e seu desenvolvimento, e a necessidade de dar mais ou menos liberdade aos seus funcionários no sentido, de manter uma coesão com os objetivos organizacionais, sem privar os indivíduos que fazem parte do quadro de funcionários da empresa, de aspectos, como criatividade e inovação dos procedimentos e decisões e de criação. Quando isto for interessante para o alcance dos objetivos. Ou em contrapartida, ao buscar 
melhor controle e racionalidade de procedimentos, no caso, onde não se objetiva que o funcionário exerça além daquilo que fora previamente estabelecido.

Em todo o caso, é de suma importância observar que as pessoas não são máquinas, e que seu aspecto humano, ou seja, sua individualidade, sempre estará presente na realização das atividades, e isto, pode ser um fator de menor motivação e também de menor resultado, sendo interessante para próximas pesquisas, verificar como a motivação e a individualidade influenciam no processo de obtenção de resultados, em situações de grande formalização ou baixa formalização. 


\section{The Risks of Formalization to Small Companies}

Abstract: This article aims to discuss the influence of organizational structure on the performance of the organizations activities and its reflection in organizational behavior, analyzing the drawbacks of excessive formalization for small companies, not failing to understand also that the lack of formalization can derail the company in different ways, for example, in customer services, the current legislation, suppliers and even the rights of their employees, so it is also important to analyze that a well-established organizational structure is a prerequisite of "healthy organizational", but it is not the health itself that will determine the clarity and perfection of the structure, but what ensures the success of the organization's performance achieved through good management of this organization.

Keywords: Organizational Structure; formalization.

\section{Referências bibliográficas}

CHIAVENATO, Idalberto. Comportamento Organizacional: A Dinâmica do Sucesso das Organizações. $2^{\circ}$ Edição, Editora Elsevier, Rio de Janeiro: 2005.

CHIAVENTAO, Idalberto. Introdução à Teoria Geral da Administração. $8^{\circ}$ Ed. Editora Elsevier, Rio de Janeiro 2011.

DRUCKER, Peter F. Administração, tarefas, responsabilidades, práticas. $2^{\circ}$ Ed. Editora Pioneira. São Paulo: 1975.

HALL, Richard H. Organizations: structures, processes and outcomes. 7.ed. Editora Prentice Hall. New Jersey: 1998.

MAXIMIANO, A. C. A. Teoria Geral da Administração: da escola científica à competitividade em economia globalizada. Editora Atlas. São Paulo: 1997. 
MINTZBERG, Henry. Criando Organizações Eficazes. Editora Atlas. São Paulo: 1995.

MOTTA, Fernando Cláudio Prestes. Teoria Geral da Administração. Editora Pioneira Thomson Learning. São Paulo: 2002.

ROBBINS, Stephen P. Administração: mudanças e perspectivas. Editora Saraiva. São Paulo: 2002.

ROBBINS, Stephen P. Comportamento Organizacional. Editora Pearson Prentice Hall. São Paulo: 2007.

SEBRAE:<HTTP://www.brasil.gov/economia-e-emprego/2012/02/o-mapadas-micro-e-pequenas-empresas,> Acesso dia 13/08/2014 as 00h09min. 